\title{
Microwave-assisted synthesis of hollow microspheres with multicomponent nanocores for heavy-metal removal and magnetic sensing
}

Lei $\mathrm{Bi}^{\dagger}$, Xuan Luan ${ }^{\uparrow}$, Fanglan Geng ${ }^{\ddagger}$, Xiuli $\mathrm{Xu}^{\dagger}$, Yiping Chen $* \S_{\text {and }}$ Feng Zhang* ${ }^{\dagger}$

$\S$ College of Food Science and Technology, Huazhong Agricultural University, Wuhan, 430070, China

$\dagger$ Key Laboratory of Environmental Nanotechnology and Health Effects, Research Center for Eco-Environmental Sciences, Chinese Academy of Sciences, Beijing 100085, China

\$ State Key Laboratory of Environmental Chemistry and Ecotoxicology, Research Center for Eco-Environmental Sciences, Chinese Academy of Sciences, Beijing 100085, China

\# Institute of Food Safety, Chinese Academy of Inspection \& Quarantine, Beijing 100176, China

f Waters Technology (Beijing) Co., Ltd. Beijing 100176, China

*Corresponding Author:

E-mail: chenyiping@mail.hzau.edu.cn; fengzhang@126.com 

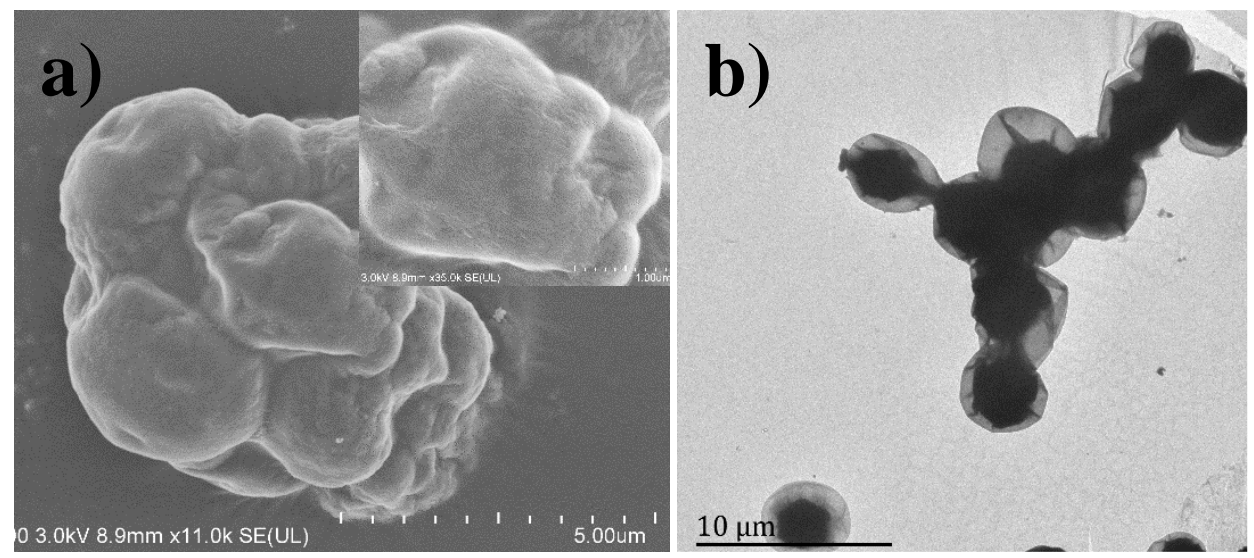

Figure S1. a) and b) are SEM and TEM images of Chlorella precursor, respectively.

The inset in a) is a close view of an individual Chlorella

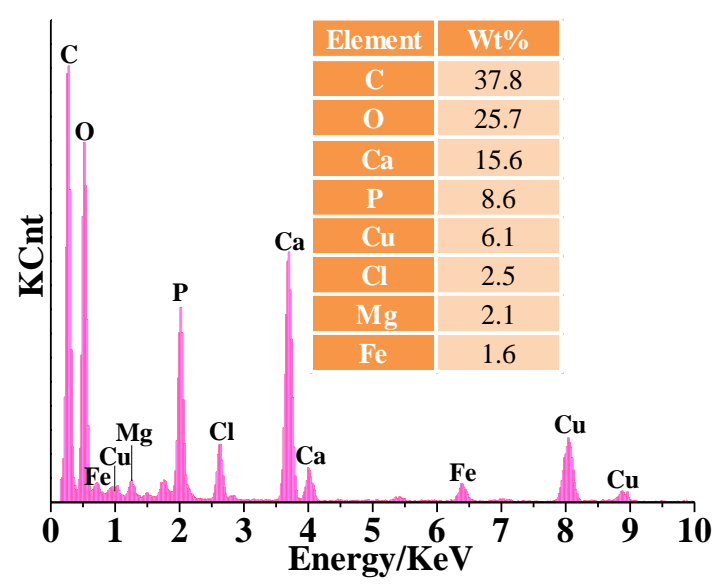

Figure S2. is the spectrum of the composition of the nanocores in blue circle (2) from Figure 1-e obtained from EDX analysis; the inset is the relative content of elements.

Table S1. Element content of the samples obtained from the XRF analysis

\begin{tabular}{|c|c|c|c|c|c|c|c|c|c|c|}
\hline & $\mathrm{Ca}$ & $\mathbf{P}$ & $\mathrm{Fe}$ & Si & $\mathrm{Mg}$ & $\mathbf{K}$ & $\mathrm{Cl}$ & $\mathbf{S}$ & $\mathrm{Na}$ & $\mathrm{Co} / \mathrm{mg} \mathrm{g}^{-1}$ \\
\hline $\begin{array}{l}\text { Chlorella } \\
\text { HMMNs }\end{array}$ & $\begin{array}{c}6.9 \pm 0.4 \\
69.6 \pm 1.5\end{array}$ & $\begin{array}{r}12.2 \pm 0.4 \\
39.8 \pm 0.7\end{array}$ & $\begin{array}{c}2.3 \pm 0.1 \\
30.4 \pm 0.8\end{array}$ & $\begin{array}{c}1.01 \pm 0.05 \\
23.7 \pm 1.2\end{array}$ & $\begin{array}{c}3.9 \pm 0.2 \\
16.3 \pm 1.2\end{array}$ & $\begin{array}{l}4.4 \pm 0.2 \\
2.1 \pm 0.10\end{array}$ & $\begin{array}{c}5.1 \pm 0.3 \\
0.49 \pm 0.09\end{array}$ & $\begin{array}{l}9.4 \pm 0.3 \\
1.7 \pm 0.1\end{array}$ & $\begin{array}{c}12.2 \pm 0.5 \\
1.8 \pm 0.1\end{array}$ & $\begin{array}{c}0.02 \pm 0.001 \\
0.23 \pm 0.01\end{array}$ \\
\hline
\end{tabular}




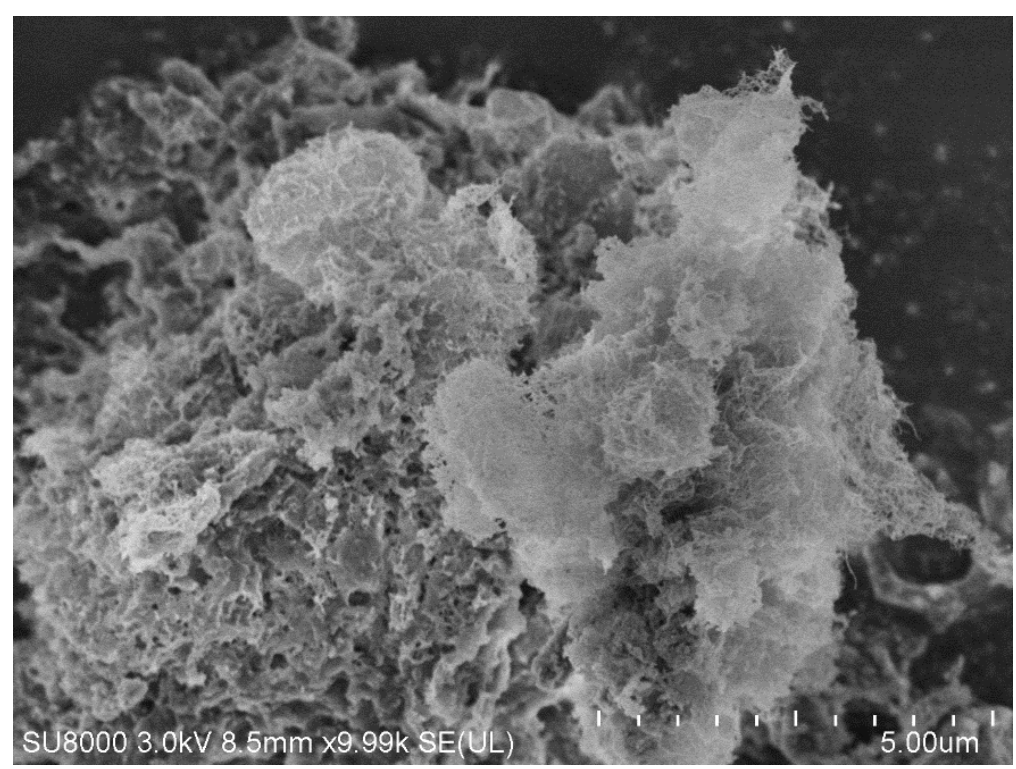

Figure S3. SEM image for the product $\left(180^{\circ} \mathrm{C}, 5 \mathrm{~h}\right)$

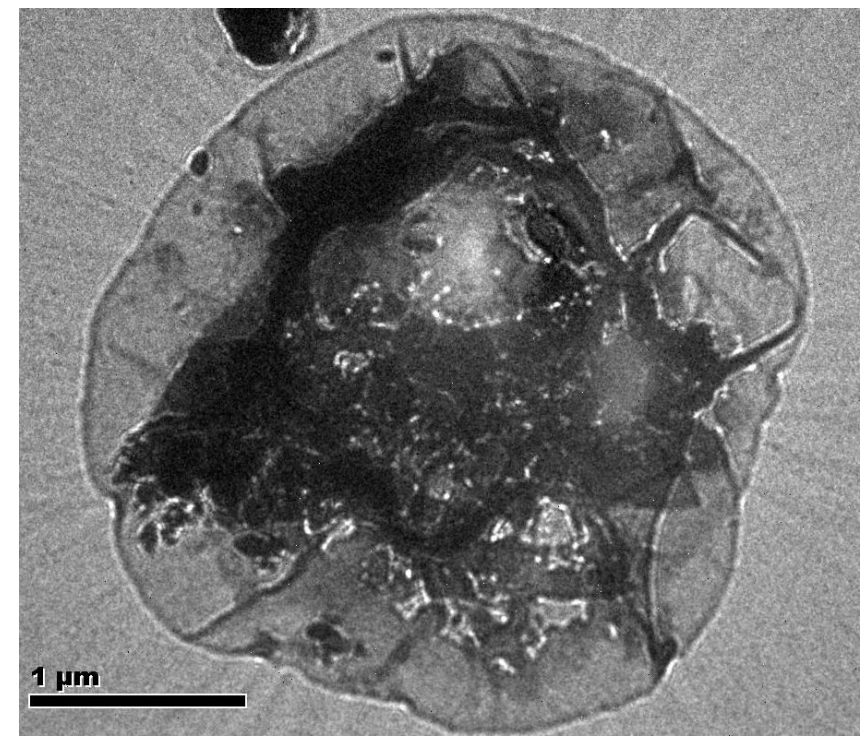

Figure S4. The TEM image of hot alkali treated Chlorella 


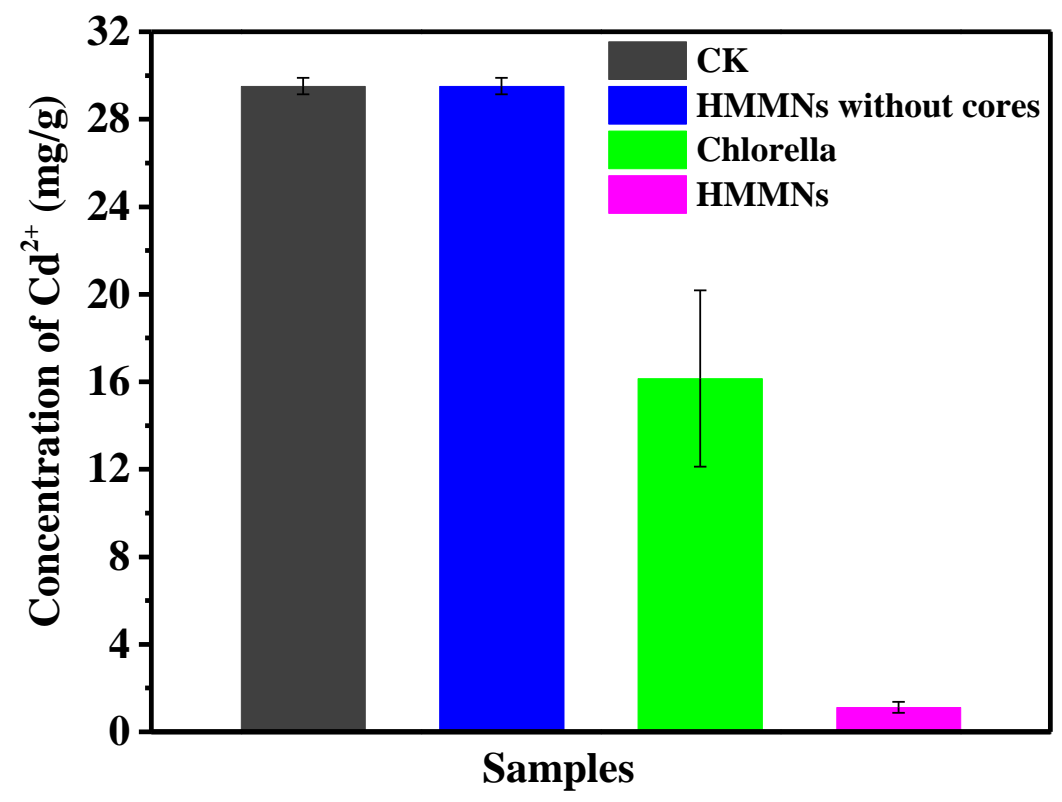

Figure S5. The removal efficiency of $\mathrm{Cd}^{2+}$ using various samples. $50 \mathrm{mg}$ of sample were added to $100 \mathrm{~mL}$ of cadmium solution with an initial $\mathrm{Cd}^{2+}$ concentration of 30 $\mathrm{mg} / \mathrm{L}$ and $\mathrm{pH}=6$.

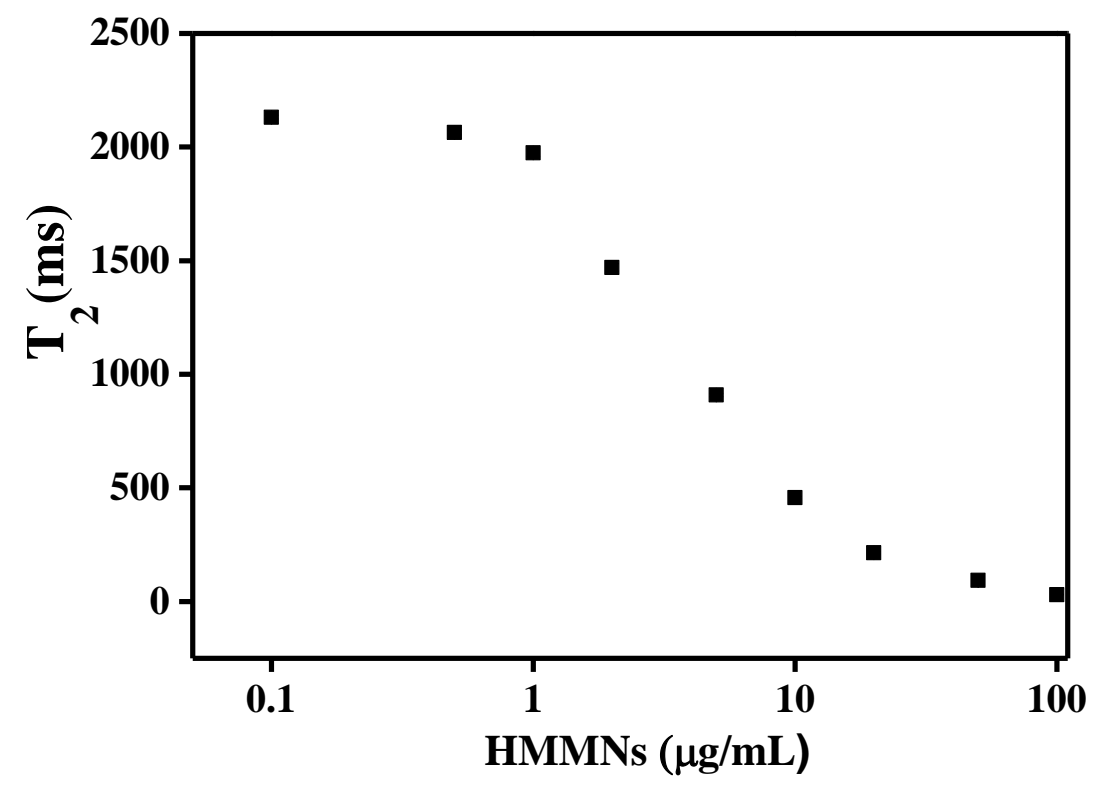

Figure S6. Relationship between the concentrations of HMMNs and the transverse relaxation time $\left(\mathrm{T}_{2}\right)$ of surrounding water molecules 


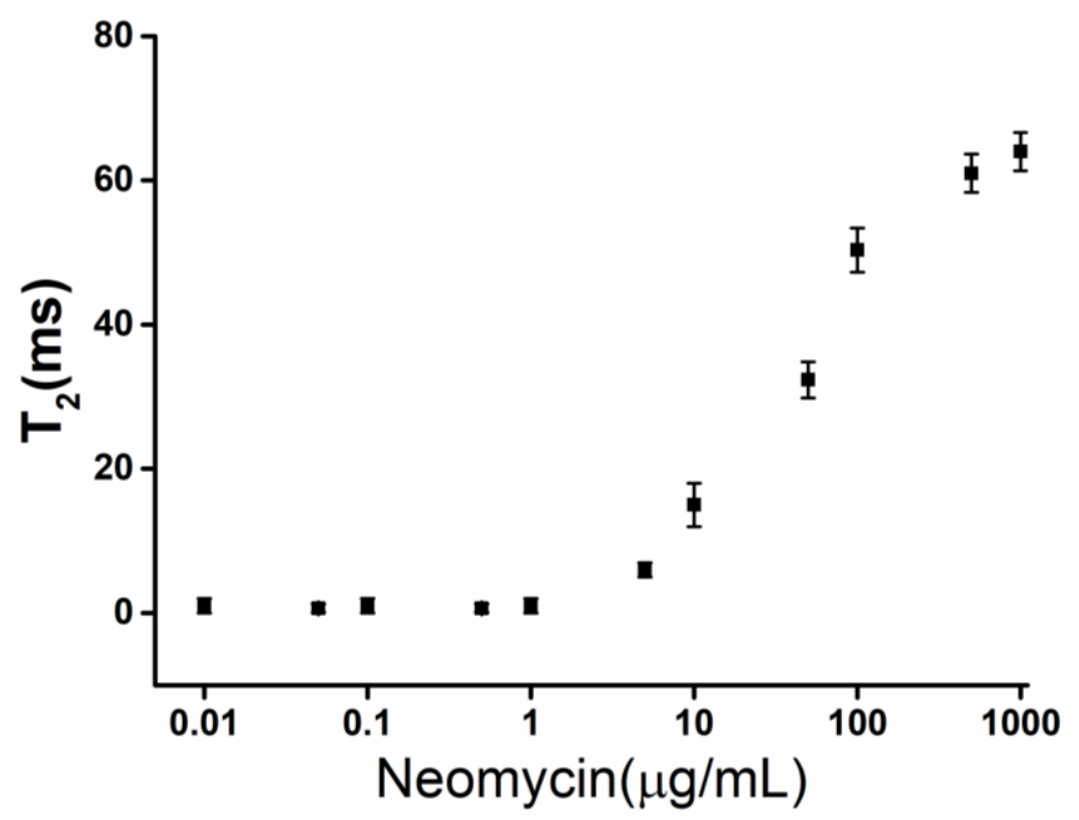

Figure S7. The standard curve of the conventional MRS biosensor for detection of neomycin, with the concentration of neomycin ranging from $0.01 \mu \mathrm{g} / \mathrm{mL}$ to 1000 $\mu \mathrm{g} / \mathrm{mL}$.

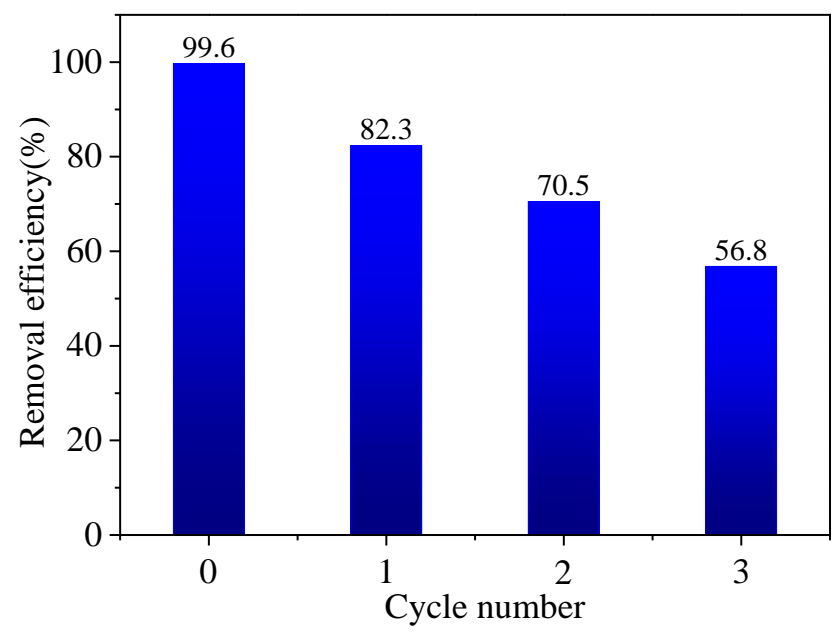

Figure S8. Cycle performance for $\mathrm{Cd}^{2+}$ removal in aqueous solution $(0.5 \mathrm{~g} / \mathrm{L}$ HMMNs were incubated at $25{ }^{\circ} \mathrm{C}$ in a $\mathrm{Cd}^{2+}$ solution with an initial concentration of $10 \mathrm{mg} / \mathrm{L}$ and a $\mathrm{pH}$ of 6$)$.

To investigate the cycle performance of HMMNs for $\mathrm{Cd}^{2+}$ removal, the $\mathrm{Cd}^{2+}$ loaded HMMNs was regenerated upon rinse with $\mathrm{HNO}_{3}(0.1 \mathrm{M})$. the regenerated HMMNs 
was then subjected to the next round $\mathrm{Cd}^{2+}$ removal. It should be noted that the removal efficiency of $\mathrm{HMMNs}$ for $\mathrm{Cd}^{2+}$ decreased from $99.6 \%$ to $56.8 \%$ after three times recycling (Figure S8), which may due to the loss of $\mathrm{Ca}, \mathrm{Mg}$ active species. And, the use of strong acidity during the regeneration processes may dissolve the nanocores.

Table S2. The results of HMMNs-based MRS for detection of neomycin in spiked milk samples

\begin{tabular}{|c|c|c|c|}
\hline $\begin{array}{c}\text { Spiked concentrations } \\
(\mu \mathrm{g} / \mathrm{mL})\end{array}$ & $\begin{array}{c}\text { Found concentrations } \\
(\mu \mathrm{g} / \mathrm{mL})\end{array}$ & Recoveries & $\mathrm{CV}$ \\
\hline 5 & 4.06 & 81.2 & 15.5 \\
\hline 10 & 8.36 & 83.6 & 13.6 \\
\hline 20 & 17.7 & 88.5 & 10.2 \\
\hline 50 & 56.3 & 112.6 & 9.6 \\
\hline 100 & 91.3 & 91.3 & 9.3 \\
\hline
\end{tabular}

Table S3. The comparison between HMMN-based MRS and other biosensors for detection of neomycin

\begin{tabular}{|c|c|c|c|}
\hline Assays & LOD & LOQ & Linear range \\
& $(\mu \mathrm{g} / \mathrm{mL})$ & $(\mu \mathrm{g} / \mathrm{mL})$ & $(\mu \mathrm{g} / \mathrm{mL})$ \\
\hline HMMN-based MRS & 0.1 & 0.5 & $0.5-100$ \\
\hline
\end{tabular}




\begin{tabular}{|c|c|c|c|}
\hline Conventional MRS biosensor & 2.5 & 10 & $10-100$ \\
\hline Paper-based colorimetric & & 1 & $1-100$ \\
Biosensor (Analyst, 2018, 143, & 0.5 & & \\
4623-4629) & & 0.1 & $0.1-100$ \\
\hline Optical Fiber-Mediated Immunosensor & 0.03 & & \\
(ACS Sens. 2019, 4, 1864-1872) & & & \\
\hline
\end{tabular}

Table S4. The cost of HMMNs and other materials in $\mathrm{Cd}^{2+}$ removal. (The cost was calculated based on the assumption of materials and energy used for synthesis in

Chinese market)

\begin{tabular}{|c|c|c|c|}
\hline Adsorbents & Price $\mathbf{( \$ / k g )}$ & Adsorption capacity $(\mathbf{m m o l} / \mathbf{k g})$ & Cost $\left(\mathbf{\$} / \mathbf{m o l}\left(\mathbf{C d}^{2+}\right)\right)$ \\
\hline Carbon nanotube & 1315.8 & 592.5 & 2220.8 \\
\hline Graphene & 877.2 & 825.5 & 1062.6 \\
\hline $\mathrm{HMMNs}$ & 438.6 & 1035.8 & 423.4 \\
\hline $\mathrm{CoFe}_{2} \mathrm{O}_{4}$ & 43.9 & 617.4 & 71.1 \\
\hline Commercial active carbon & 4.4 & 93.9 & 46.9 \\
\hline Magnetic oak wood biochar & 0.5 & 65.8 & 7.6 \\
\hline
\end{tabular}

The cost of HMMNs is $438.6 \$ \mathrm{~kg}^{-1}$ and the cost for removing $1 \mathrm{~mol} \mathrm{of} \mathrm{Cd}^{2+}$ is 423.4 \$. The coat of HMMNs is higher than that of the commercial active carbon and magnetic oak wood biochar, but is lower than that of the carbon nanotubes and grapheme (Table S4). However, the commercial dynabeads magnetic beads (Invitrogen, Thermo Fisher Scientific) for magnetic biosensor is at least $1462 \$ / \mathrm{g}$, which is more expensive than that of HMMNs. 